\title{
Physical and Paste Properties Comparison of Four Snacks Produced by High Protein Quinoa Flour Extrusion Cooking
}

\author{
Karen Sofia Muñoz-Pabon ${ }^{1,2 *}$, Astrid Soraya Parra-Polanco ${ }^{2}$, \\ Diego Fernando Roa-Acosta ${ }^{2}$, Jose Luis Hoyos-Concha ${ }^{2}$ and \\ Jesus Eduardo Bravo-Gomez ${ }^{2}$
}

${ }^{1}$ GIEPRONAL Research Group, School of Basic Sciences, Technology and Engineering, Universidad Nacional Abierta y a Distancia (UNAD), Bogotá, Colombia, ${ }^{2}$ Departamento de Agroindustria, Facultad de Ciencias Agrarias, Universidad del Cauca, Popayán, Colombia

\section{OPEN ACCESS}

Edited by:

Leonardo Sepúlveda,

Autonomous University of

Coahuila, Mexico

Reviewed by:

B. N. Dar,

Islamic University of Science and

Technology, India

Sajad Ahmad Wani,

Islamic University of Science and

Technology, India

*Correspondence:

Karen Sofia Muñoz-Pabon

kspabon@unicauca.edu.co

Specialty section:

This article was submitted to

Sustainable Food Processing,

a section of the journal

Frontiers in Sustainable Food Systems

Received: 10 January 2022 Accepted: 04 February 2022

Published: 03 March 2022

Citation:

Muñoz-Pabon KS, Parra-Polanco AS,

Roa-Acosta DF, Hoyos-Concha JL and Bravo-Gomez JE (2022) Physical and Paste Properties Comparison of Four Snacks Produced by High Protein Quinoa Flour Extrusion

Cooking.

Front. Sustain. Food Syst. 6:852224. doi: 10.3389/fsufs.2022.852224
Extrusion cooking is used to produce puffed snacks based on cereals and feed ingredients. Because of its nutritional properties, quinoa flour has been employed to prepare various types of foods. This study evaluates the effects of including hyper-protein quinoa flour obtained through abrasive milling in four formulations cooked at $27 \%$ moisture content and processed in a laboratory level single screw extruder to determine their physical, textural, and pasting properties. The results indicated that additional hyper-protein quinoa flour in the cereal mixture reduced $47 \%$ the expansion index (El), while the extrudate density (ED) and hardness increased 54 and 130\%, respectively. After the extrusion process, the water absorption index (WAI), water solubility index (WSI) increased by more than 100\%. The addition of hyper-protein quinoa flour (25-37\%) did not affect the WAI, but an increase in the WSI was observed. The quinoa flour extrusion process generated changes on the color mainly in the $L$ parameter, which decreased in the extruded snacks with quinoa flour inclusion (51.49), compared to the snack without inclusion (62.68). Changing the integrity of the starch granules and associated proteins, causing a decrease in the viscosity peaks during heating and subsequent cooling. The extruded samples revealed stability in the retrogradation process. Extruded snacks from quinoa could be an alternative approach to produce feed ingredients with high protein contents.

Keywords: extrusion cooking, snack, cereals, high-protein quinoa flour, rheological properties, physical properties

\section{INTRODUCTION}

Extrusion cooking is a versatile technique used for decades to formulate cereal-based snacks through a process that involves higher temperature and short-term cooking. This process uses rice or corn flours to produce expanded ready-to-eat snacks (Tas and Shah, 2021), that have a pleasant tasting, and are energy dense, low in protein, and high in starch, calories, fat, sodium and refined carbohydrates (Schlinkert et al., 2020). For this reason, the food industry is in search of alternative naturally grown grains that offer a valuable nutritional profile that adapt to adverse climatic conditions, for example, quinoa (Chenopodium quinoa) is a grain native to the Andes of 
South America, where it has been a staple food since preHispanic times. This type of gluten-free grain is a food alternative for celiac or gluten-sensitive people due to its protein quality and high content of fiber and bioactive compounds (Sezgin and Sanlier, 2019).

Quinoa (Chenopodium quinoa Willd) belongs to the pseudocereal group, and has complete nutritional properties, because of its balance of amino acids, high content of unsaturated fatty acids, dietary fiber, vitamins and minerals. Quinoa has technological properties such as solubility, water retention capacity, gelation, emulsion, and foam that allow expanded uses, and presents a proportion of omega- 6 and a prominent vitamin E content. The starch present in quinoa has some physicochemical properties relevant to the industry, such as viscosity and freezing stability (Abugoch, 2009). Quinoa is recognized for its remarkable amounts of phytochemicals, such as polyphenols, phytosterols, and flavonoids.

Quinoa grains are single-seeded achenes with the pericarp adhered to the head. The crescent-shaped embryo surrounding the perisperm has the greatest supply of protein and comprises two cotyledons while the starch is stored in the perisperm, constituting $40 \%$ of the grain volume and comprising thinwalled cells. Quinoa grains need special conditions for milling and dehulling. The dry milling process is the repetitive steps of crushing, sieving, separating, and grinding to extract the endosperm from the grain by physical methods to obtain a hiper- protein quinoa flour (HPQF) at a low cost and reduced environmental impact (Reichert and Youngs, 1976; Caperuto et al., 2001; Avila Ruiz et al., 2016; D’Amico et al., 2019; Roa et al., 2019). Structural, rheological, and functional properties have been studied (Haros, 2017; Roa-Acosta et al., 2020; Polo et al., 2021) and have shown potential to be included in foods.

Increasing the protein content of snacks by adding legume meals is considered a good initiative to reduce the environmental impact generated by reliance on animal species to supply protein demands (Tas and Shah, 2021). There are several extruded snacks with added legumes in the market and increased inclusion will continue to drive the global market. There are more quinoabased products, such as bread flour, snack, breakfast cereals, pasta, cookies, and biodegradable films (Wang and Zhu, 2016). As this pseudo-cereal has valuable nutritional and physiological properties, which could help promote consuming these products, compared to the other cereals the total protein content of quinoa $[16.3 \%$ on a dry basis (bs)] is higher than barley $(11 \%$ bs) rice $(7.5 \%$ bs $)$ or corn $(13.4 \% \mathrm{bs})$, and is comparable to that of wheat $(15.4 \% \mathrm{bs})$, although compared to cereal grains, quinoa proteins are high in lysine, the limiting amino acid in most cereal grains, its essential amino acid balance is excellent because of a wider range of amino acids than cereals and legumes, with higher lysine (5.1-6.4\%) and methionine (0.4-1\%) (Abugoch, 2009).

Martin et al. (2020) found a high potential in producing snacks employing mixtures of legume protein isolates/concentrates, in particular lupin protein isolates and pseudo-cereal flours such as quinoa to increase the nutritional value of protein-rich extrudates, and reduce the toughness of snacks at protein concentrations of 70\%. Furthermore, Zapana et al. (2020) obtained puffed quinoa snacks by combining a Gun and extrusion puffing process, which resulted in a satisfactory quality, avoiding the loss of nutritional properties with an adequate bioavailability of organic matter and proteins compared to microwave puffed quinoa. In addition to nutritional spets the incorporation of unconventional grains also has an effect on physical properties, for example, the most notable effect in the incorporation of quinoa flour between 20 and $50 \%$ in combination with amaranth and kaniwa was the alteration of internal structures, resulting in smaller pores, increasing hardness and reducing crunchiness (Ramos Diaz et al., 2015).

Since there is little research on obtaining snacks from high protein quinoa, the aim of this study was to determine the effect of adding quinoa flour to a cereal mixture in different proportions on the properties of the extrudates.

\section{MATERIALS AND METHODS}

\section{Materials}

The cereals used were produced in 2020 and obtained from "SEGALCO" Company S.A.S. Popayán, Colombia. "SEGALCO" Company provided the quinoa and a polishing machine (500$\mathrm{T}$, Mavimar, Colombia) was used with a processing capacity of $60 \mathrm{Kg} / \mathrm{h}$, the operative system functioned through rock or stone discs, connected to a central shaft, which rotate inside a cylinder with $1 \mathrm{~mm}$ perforations, processing a polished grain, and quinoa hyper-protein flour (HPQF).

\section{Development of Snack Pellets}

The multigrain snack pellets were made according to the formulations shown in Table 1, composed of a cereal blend (CB) corn flour, rice flour, cornstarch and hyper-protein quinoa flour (HPQF), in a single screw extruder. The mixtures were wetted to $27 \%$ by spraying the calculated volume of water and mixing in a laboratory blender. The samples were packed in polyethylene bags and stored in the refrigerator overnight at $4^{\circ} \mathrm{C}$ to equilibrate the moisture. Before extrusion cooking, the samples underwent room temperature, then subjected to the extrusion-cooking process extruder temperature profile: $140^{\circ} \mathrm{C}$, screw rotation speed was $200 \mathrm{rpm}$, nozzle diameter was $3 \mathrm{~mm}$. The snacks were dried at $60^{\circ} \mathrm{C}$ for $17 \mathrm{~h}$.

\section{Proximate Composition}

Quantification of protein (A.O.A.C 2005, Method 955.39), fat (A.O.A.C 2005, Method 920.85), fiber (A.O.A. C 2005, Method 945.38), and moisture (A.O.A.C 2005, Method 925.10), contained in the samples. Carbohydrates contents were calculated by difference as $100-$ (proteins + fat + water + ash). Values were expressed on a dry weight basis.

\section{Extrudate Density and Expansion Index}

Extrudate density (ED) was measured according to the method described by Li et al. (2019), with samples $(n=10)$, using chia 
TABLE 1 | Multi-cereal blends (CB) used in the extrusion process.

\begin{tabular}{lcccc}
\hline Sample & CB: HPQF 75:25 & CB: HPQF 70:30 & CB: HPQF 63:37 & CB: HPQF 100:0 \\
\hline CF (\%) & 58.5 & 54.6 & 49.14 & 78 \\
RF (\%) & 7.5 & 7 & 6.3 & 10 \\
CS (\%) & 9 & 8.4 & 7.56 & 12 \\
HPQF (\%) & 25 & 30 & 37 & - \\
\hline
\end{tabular}

CF, corn flour; RF, rice flour; CS, corn starch; HPQF, High protein quinoa flour.

seeds, and calculated using Equation (1):

$$
D E=\frac{P E}{V E}=\frac{P E}{\frac{P s}{\rho s}}
$$

$\mathrm{PE}$ and VE are the weight and equivalent volume of the extrudate; $\rho$ s and Ws represent the density and weight of the chia seeds. ED measurements were performed fifteen times.

The expansion index (EI) was determined by dividing the radial diameter of the extrudate, measured with a caliper, by the extruder die bore diameter $(3 \mathrm{~mm})$. Expansion index measurements for each extrusion series $(n=15)$, and a mean value was recorded.

\section{Texture Properties}

The mechanical properties of the extrudates were determined using a texture analyzer (Shimadzu EZ TEST SM, model 500N168, Japan). Twenty-five extrudates from each treatment were equilibrated to a moisture content of $8.0 \pm 0.5 \%$ (wb) using a humidity chamber (30\% RH, $94 \mathrm{~h}$ ). Samples were compressed perpendicular to the extrusion direction to $50 \%$ of their original diameter with a $5 \mathrm{~mm}$ compression punch at a test speed of $1.0 \mathrm{~mm} / \mathrm{s}$. The area under the curve (S; N.mm) and the number of peaks $(\mathrm{n})$ above $1.5 \mathrm{~N}$ were obtained from the force-strain curves and used to calculate the spatial frequency of ruptures (Nsr), average crushing force ( $\mathrm{Fcr}$ ), and work of crispness (Wc), following the method of Karkle et al. (2012), with slight modifications.

$$
\begin{aligned}
N s r\left(m^{-1}\right) & =n / d \\
F(N) & =S / d \\
W c(N . m m) & =F / N s r
\end{aligned}
$$

where $d=$ probe travel distance $(\mathrm{mm})$.

\section{Water Absorption Index and Water Solubility Index}

The method described by Wani and Kumar (2016) was used to determine water absorption index (WAI) and water solubility index (WSI). The following were used $10 \mathrm{~mL}$ of distilled water was transferred into a $15 \mathrm{~mL}$ falcon tube. The extrudates were ground and sieved through a $100 \mu \mathrm{m}$ sieve. $0.5 \mathrm{~g}$ of ground and sieved extrudate was added to the water in the falcon tube. The mixture was shaken in chambered orbital shaker (MaxQ 4450, Thermo Scientific, Germany), for $60 \mathrm{~min}$. The tubes were centrifuged ( $\mathrm{Z}$ 326, Hermle, Germany) at 3,000 $\times \mathrm{g}$ for $10 \mathrm{~min}$ at $25^{\circ} \mathrm{C}$. After centrifugation, the supernatant was at once transferred to a plate and dried in an air oven (ED1 115, Binder, Germany) at $90^{\circ} \mathrm{C}$ overnight. The supernatant cooled for $30 \mathrm{~min}$ to room temperature and weighed. WSI was calculated by Equation (5) and WAI was calculated by Equation (6). All experiments were performed in triplicate.

$$
\begin{aligned}
\text { WSI }(\%) & =\frac{\text { weight of dry solids in supernatant }}{\text { dry weight of sample }} \times 100 \\
W A I\left(\frac{g}{g}\right) & =\frac{\text { weight of gel }}{\text { mdry weight of sample }}
\end{aligned}
$$

\section{Color}

The color of the extrudate $(n=3)$ was determined using a Konica Minolta Spectrophotometer CM-5, controlled by SpectraMagic NX software, with D65 illuminant and $10^{\circ}$ observer angle. The samples were analyzed in triplicate, taking $5 \mathrm{~g}$ of sample. Luminosity (L) and chromaticity parameters $\mathrm{a}^{*}(-\mathrm{a} *=$ green and $+\mathrm{a}^{*}=$ redness $)$ and $\mathrm{b}^{*}\left(-\mathrm{b}^{*}=\right.$ blue and $+\mathrm{b}^{*}=$ yellow) were measured. The total color change $(E)$ was calculated as Equation (7).

$$
\Delta E=\sqrt{\left(L-L_{0}\right)^{2}+\left(b-b_{0}\right)^{2}+\left(a-a_{0}\right)}
$$

\section{Pasting Properties}

The rheological properties of each dispersion were determined using a rheometer (TA INSTRUMENTS, AR 1500, New Castel, USA), equipped with a starch pasting cell used to evaluate the pasting properties of extrudates and non-extruded blends. Three gram (12\% moisture basis) of ground and sieved sample $(100 \mu \mathrm{m})$ and $22 \mathrm{ml}$ of distilled water were mixed to obtain a paste in an aluminum pot. The shear rate was kept constant at $16.75 \mathrm{~s}-1$, throughout the heating range $\left(25^{\circ} \mathrm{C}-95^{\circ} \mathrm{C}-25^{\circ} \mathrm{C}\right)$ while the heating rate was $10^{\circ} \mathrm{C} / \mathrm{min}$. Peak viscosity (PV), viscosity drop $(\mathrm{BD})$, and set back $(\mathrm{SB})$ were recorded in duplicate (Pasqualone et al., 2021). Using the Savistky-Golay function, the data was smoothed in GraphPad Prism version 6.

\section{Statistical Analysis}

A one-way factorial design with four levels of factor quantity of high protein quinoa flour and $n=3$ independent replications was used in each treatment. The experimental data was analyzed by analysis of variance (ANOVA) and Tukey's test, defining significance as $p<0.05$. All statistical analyses were carried out with GraphPad Prism 5.0 software. 
TABLE 2 | Quantification of moisture, lipids, and protein of raw materials for the validation of hyper-protein flour.

\begin{tabular}{|c|c|c|c|c|}
\hline Sample & Moisture (\%) & Lipids (\%) & Protein (\%) & Fiber (\%) \\
\hline \multicolumn{5}{|c|}{ Raw materials } \\
\hline HPQF & $4.24 \pm 0.03$ & $18.82 \pm 0.86$ & $30.12 \pm 0.68$ & $9.30 \pm 0.70$ \\
\hline RF & $10.66 \pm 0.19$ & $0.83 \pm 0.03$ & $9.4 \pm 0.45$ & $7.222 \pm 0.389$ \\
\hline CF & $7.95 \pm 0.36$ & $2.22 \pm 0.23$ & $7 \pm 0.23$ & $6.874 \pm 0.008$ \\
\hline CB: HPQF 70:30 & $8.37 \pm 0.23^{b}$ & $5.27 \pm 0.7^{b}$ & $14.19 \pm 0.11^{\mathrm{b}}$ & $6.1 \pm 0.07^{c}$ \\
\hline CB: HPQF 63:37 & $7.66 \pm 0.10^{c}$ & $6.72 \pm 0.05^{\mathrm{a}}$ & $16.20 \pm 0.08^{a}$ & $7.45 \pm 0.02^{\mathrm{a}}$ \\
\hline CB: HPQF 100:0 & $9.11 \pm 0.02^{\mathrm{a}}$ & $2.13 \pm 0.07^{d}$ & $7.03 \pm 0.09^{d}$ & $5.1 \pm 0.04^{d}$ \\
\hline
\end{tabular}

$C B$, cereal blend.

*WGQ, whole grain quinoa; CF, corn flour; RF, rice flour; CS, corn starch; HPQF, High protein quinoa flour.

For each parameter, different letters indicate significant differences at $p<0.05$.

TABLE 3 | Extrusion density (ED) and expansion index (El).

\begin{tabular}{lccc}
\hline Sample & El & ED Kg/L & $\mathbf{a}_{\mathrm{w}}$ \\
\hline CB: HPQF 75:25 & $1.81 \pm 0.06^{\mathrm{b}}$ & $0.49 \pm 0.09^{\mathrm{bc}}$ & $0.38 \pm 0.01^{\mathrm{b}}$ \\
CB: HPQF 70:30 & $1.79 \pm 0.12^{\mathrm{b}}$ & $0.55 \pm 0.09^{\mathrm{b}}$ & $0.37 \pm 0.02^{\mathrm{b}}$ \\
CB: HPQF 63:37 & $1.22 \pm 0.03^{\mathrm{c}}$ & $0.65 \pm 0.09^{\mathrm{a}}$ & $0.36 \pm 0.01^{\mathrm{b}}$ \\
CB: HPQF 100:0 & $2.31 \pm 0.23^{\mathrm{a}}$ & $0.42 \pm 0.04^{\mathrm{c}}$ & $0.42 \pm 0.03^{\mathrm{a}}$
\end{tabular}

For each parameter, different letters indicate significant differences at $p<0.05$.

\section{RESULTS AND DISCUSSION}

The aim of the study was to determine the production potential of cereal extrudates adding HPQF, which has health-promoting components. According to preliminary research, the maximum proportion of quinoa that could be added to $\mathrm{CB}$ to produce a sensory acceptable product was $37 \%$. Therefore, quinoa was added at 25,30 , and $37 \%$.

\section{Proximate Composition}

Table 2 shows the main composition of rice flour, maize flour, hyper-protein flour, whole quinoa seed, and snacks. The protein content reported for whole quinoa seed was comparable to data presented by the literature (Abugoch, 2009). The protein content of the HPQF is $53 \%$ higher than the whole quinoa, this value corroborates that the polishing process with the abrasion mill allows the removal of the pericarp which decreases the volume of dietary fiber (and saponins) but not the protein or fat content (D'Amico et al., 2019). The moisture content of the snacks is $<9.11 \%$, this percentage is a quality index that indicates that the product will be less susceptible to the effect of microbes, therefore, it will have a long stability (Sobowale et al., 2021).

The aim of adding HPQF was increasing the protein content of the snacks, nut crops have been shown to increase the protein content of snacks, as has been established with quinoa-based extrudates (Zapana et al., 2020). Table 2 shows the significant increase $(p<0.05)$ of protein, fiber and lipids with the increase of the proportion of quinoa flour while the protein values were as expected according to the proportion of HPQF included in each mixture since during the extrusion process, the effect on protein content is minimal (Gulati et al., 2020). The lipid and fiber content of the snacks increased with the addition of quinoa flour. Comparing the raw materials with sanck, a decrease in lipids was observed, due to the formation of complexes between amylose and lipids during extrusion processing, which resulted in a reduction of lipid extractability (Jabeen et al., 2021).

\section{Expansion Index}

Table 3 shows the effect of HPQF addition on the EI and ED of the extrudates. Adding HPQF, the expansion index of the extrudates decreased, while the influence of adding 25 and $30 \%$ was not significantly marked, adding $37 \%$ HPQF decreased expanding the extrudates, decreasing from 2.31 to 1.22 compared to snacks without quinoa. The formulations prepared with quinoa contain a higher proportion of protein and fiber; the latter breaks the cell walls and prevents forming air bubbles and expanding to its maximum potential (Jozinović et al., 2016). Likewise, the lipid content influences the expansion properties, in the $37 \%$ mixture, $6.72 \%$ lipids are present, which with humidities above $21 \%$ and temperature profiles above $128^{\circ} \mathrm{C}$, favor forming a starch-lipid complex, resulting in a snack with undesirable physical properties, with high density and hardness (Pilli et al., 2012). A high fat content provides a lubrication effect in the barrel at high temperatures, which reduces its expansion (Chadha et al., 2021). Shah et al. (2016) report similar studies on extrudates from grains.

\section{Extrudate Density}

The ED is a very important attribute from the point of view of commercial production of extruded products because most are filled by weight and not by volume (Tas and Shah, 2021).

The results for $\mathrm{ED}$ agree with those for expansion index, i.e., extrudates with added quinoa flour have higher $\mathrm{ED}$, proportional to the percentage of quinoa, compared to those with corn. This observation is consistent with Tas and Shah (2021) in that ED and EI are dependent attributes with an inverse relationship. As seen 


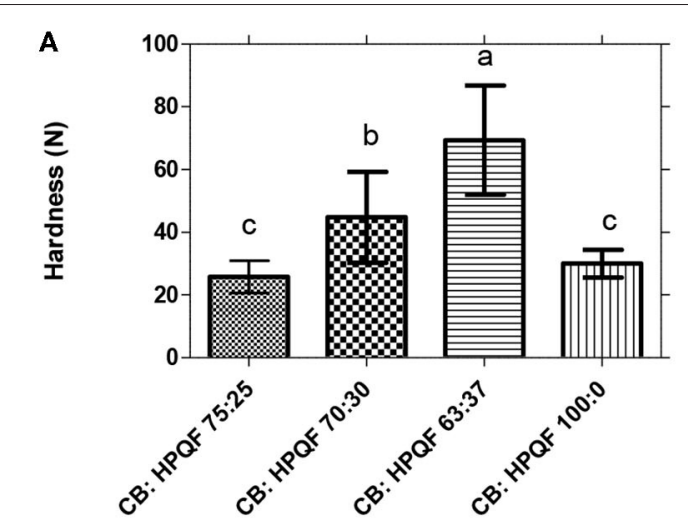

B

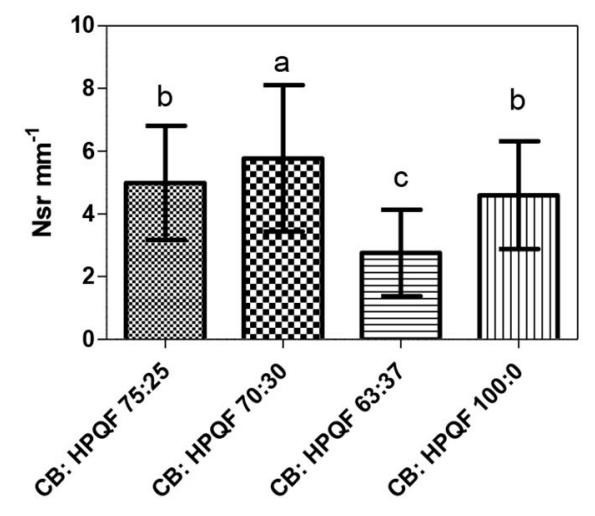

C

D
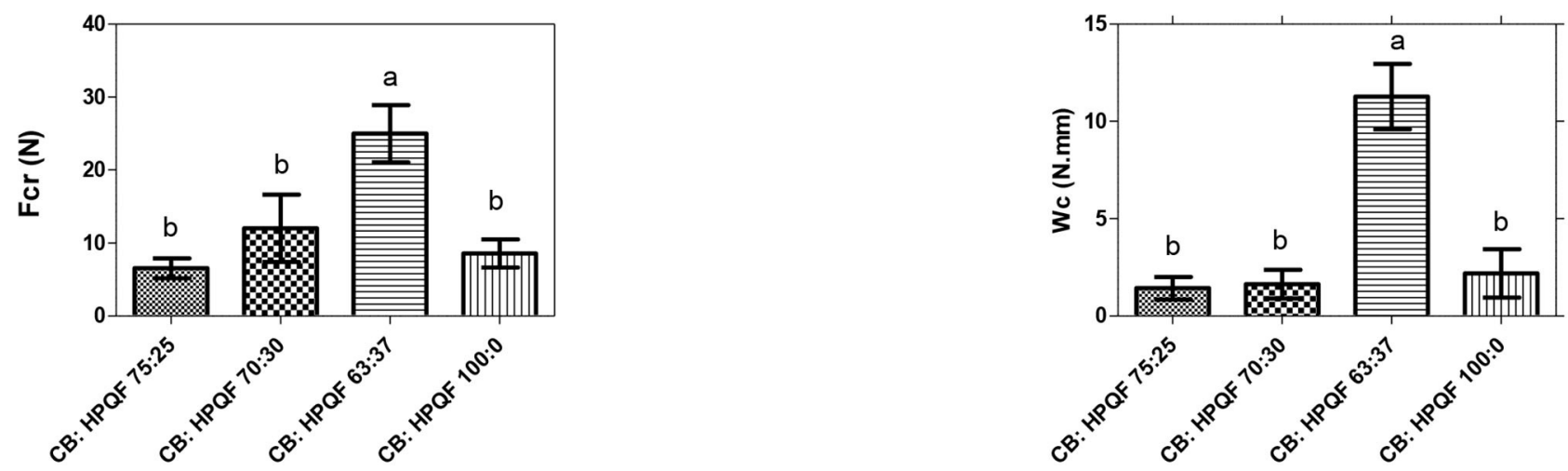

FIGURE 1 | Textural properties in the extrudates of the four formulations (A) hardness; (B) spatial frequency of ruptures (Nsr); (C) average crushing force (Fcr); and (D) crispness work (Wc). Texture parameter values followed by different lowercase letters are significantly different $(p<0.05)$.

TABLE 4 | Water absorption index (WAI) and water solubility index (WSI), color parameters.

\begin{tabular}{|c|c|c|c|c|c|c|}
\hline Samples & WAI & WSI & $L^{*}$ & $a^{*}$ & $\mathbf{b}^{*}$ & $\Delta E$ \\
\hline \multicolumn{7}{|c|}{ Extruded samples } \\
\hline CB: HPQF 75:25 & $7.32 \pm 0.19^{b}$ & $11.78 \pm 0.72^{b}$ & $54.03 \pm 0.68^{b}$ & $4.42 \pm 0.19^{c}$ & $24.43 \pm 0.44^{c}$ & 35.18 \\
\hline CB: HPQF 63:37 & $6.64 \pm 0.29^{b}$ & $13.57 \pm 0.23^{\mathrm{a}}$ & $51.49 \pm 0.76^{c}$ & $5.77 \pm 0.18^{b}$ & $28.04 \pm 0.56^{\mathrm{b}}$ & 38.02 \\
\hline CB: HPQF 100:0 & $8.38 \pm 0.25^{a}$ & $14.54 \pm 1.09^{\mathrm{a}}$ & $62.68 \pm 0.77^{a}$ & $7.33 \pm 0.48^{\mathrm{a}}$ & $37.69 \pm 1.0^{a}$ & 30.15 \\
\hline CB: HPQF 70:30 & $2.53 \pm 0.11^{\mathrm{a}}$ & $5.88 \pm 0.63^{a}$ & $80.58 \pm 0.37^{b}$ & $1.22 \pm 0.1^{\mathrm{a}}$ & $23.71 \pm 0.61^{\mathrm{a}}$ & 6.93 \\
\hline CB: HPQF 63:37 & $2.40 \pm 0.062^{\mathrm{a}}$ & $4.31 \pm 0.64^{b}$ & $81.25 \pm 0.29^{b}$ & $1.29 \pm 0.03^{\mathrm{a}}$ & $23.925 \pm 0.03^{a}$ & 8.51 \\
\hline CB: HPQF 100:0 & $2.37 \pm 0.054^{a}$ & $2.59 \pm 0.32^{c}$ & $89.06^{a} \pm 0.07^{a}$ & $1.16 \pm 0.02^{\mathrm{a}}$ & $24.45 \pm 0.01^{\mathrm{a}}$ & \\
\hline
\end{tabular}

For each parameter, different letters indicate significant differences at $p<0.05$.

in Table 3, the ED increased with quinoa composition, which has a higher fiber content compared to corn flour because the fiber undergoes minimal size reduction and remains stable during the extrusion process, thus limiting expansion and improving ED, furthermore during extrusion, a higher feed moisture content above $20 \%$ reduces the melt viscosity, leading to a drop in the vapor pressure gradient and thus causing a laminar flow of the melt restricting expansion and thus increasing the ED 
(Jabeen et al., 2021). Similar results were reported by Wani and Kumar (2016) on snacks based on fenugreek, oat and pea.

\section{Texture Properties}

Figure 1 shows the textural properties of the extrudates. Quinoa content affected the average crushing strength $\operatorname{Fcr}(p<0.05)$, the 30 and $37 \%$ blends presenting higher quinoa contents lead to higher values of Fcr, likewise these blends lead to extrudates that require higher work Wc and are harder, these extrudates presented the lowest expansion, which agrees with the results by Jozinović et al. (2016), who concluded that textural properties are influenced by the expansion degree, i.e., extrudates with higher EI had lower toughness and higher fracturability. In a study on the mechanical and microstructural properties of extrudates from corn starch with high amylose content and soy protein concentrate, Zhu et al. (2010) observed that hardness increased with the combination of decreased expansion and protein agglomeration produced by high temperature and shear.

\section{Water Absorption Index and Water Solubility Index}

WAI decreased slightly and WSI increased proportionally to the addition of quinoa flour to $\mathrm{CB}$, but after the extrusion process, both parameters increased significantly.

WAI is the measure of the volume occupied by the starch after swelling by excess water, so it can be used as an index of starch gelatinization (Tas and Shah, 2021). As shown in Table 4, the formulations affected the WAI $(p<0.05)$ of the extrudates, although there are no major differences, the formulations with quinoa present lower values regarding the extrudates with rice and corn, because there is an obstacle in the ability of starch to combine with water because of the greater interaction between the hydrophilic groups of starch and quinoa protein.

As shown in Table 4, the WAI values of extrudates are higher than raw flours because gelatinized starch absorbs water better than native starch granules at room temperature. WAI decreases when dextrinization or starch melting prevails over gelatinization (Sarawong et al., 2014).

WSI shows the degree of molecular degradation and conversion of starch and measures the soluble components released from starch after extrusion (Ye et al., 2018). As shown in Table 4, formulations affect WSI values $(p<0.05)$, presenting higher percentages in mixtures added with 30 and $37 \%$. This behavior occurs because the formulations present a higher proportion of fat and generate a plasticizing effect, while the high lipid content reduces starch degradation (Tas and Shah, 2021).

\section{Color}

Color change is a good measure of the effect of extrusion cooking on extrudates, especially $\mathrm{L}^{*}$ is the best parameter to estimate browning kinetics (Alam et al., 2016). Table 4 shows the color parameters of raw flours, extrudates added with quinoa, and those with only rice and corn.
Compared to the raw formulations, all extrudates had lower $\mathrm{L}^{*}$ (lightness) values, $\mathrm{a}^{*}$ (redness), and $\mathrm{b}^{*}$ (yellowness) values only in the extrudates containing corn and rice. The $\mathrm{a}^{*}$ and $\mathrm{b}^{*}$ values of the extrudates decreased, while the $\mathrm{L}^{*}$ value increased.

As shown in Table 4, the brightness increment in the snack without quinoa suggests an increase in air bubble nucleation sites, resulting in a higher number of cells in the snack (Li et al., 2019). In formulations with quinoa, especially snacks added with $37 \%$, when subjected to excessive dry heat and high-shear forces, dextrinization occurs in the starch, which decomposes into dextrin, altering the color of the extruded products in a yellow to brown color. This confirms the WAI results, where lower values associate with higher dextrinization.

The total color change $(\Delta \mathrm{E})$ that shows the color change compared to the raw cereal mixture without quinoa ranged from 30.15, for extruded corn to 38.02 for the cereal and HPQF mixture. According to studies by Jozinović et al. (2016), in raw and extruded cereal mixtures, most of the population perceives a total color difference higher than 3 , if the color difference is higher than 6, it is clear the colors are in different color groups. Therefore, adding HPQF to the cereal mixture results in a significant color change both before and after extrusion, as shown in Figure 2.

\section{Pasting Properties}

Table 5 shows the pasting properties of non-extruded and extruded samples. Adding HPQF and after the extrusion process, the cold and hot viscosity values decreased proportionally to the quinoa flour content. There is documentation that the molecular degradation that occurs during extrusion influences lower viscosity values for extruded starch; this decrease in viscosity suggests a molecular size of starch reduction during this process (Jozinović et al., 2016). In addition, matrix components such as fat, protein, and fiber could affect starch gelatinization by interacting (e.g., coast blinds, or complexes) with the granule and contribute to reduced melt viscosity (Ondo et al., 2013). This is consistent with the WAI results, as the fat content along with the high pressure and temperature increases in pressure inside the extruder barrel and suggests a higher level of starch degradation.

Because of starch retrogradation during cooling, after heating and mixing, the viscosity of all samples decreased and after cooling, the viscosity of all samples increased. The viscosity values of the non-extruded samples were higher considering all extruded samples, as shown in Figure 3. This suggests the result of starch damage and the lower tendency of the molecules to tightly pack during cooling. Therefore, smaller polymers have a higher number of hydroxyl groups and a higher affinity to form hydrogen bonds with water molecules; during cooling, reassociation between amylose molecules results in a gel formation and leads to an increase in the cold viscosity of the extrudates (Jozinović et al., 2016).

In this study, there was a greater viscosity reduction for extrudates without quinoa followed by quinoa flours and extrudates added with quinoa. The difference between the first and final viscosity of the starch extrudates in the pasting profile 


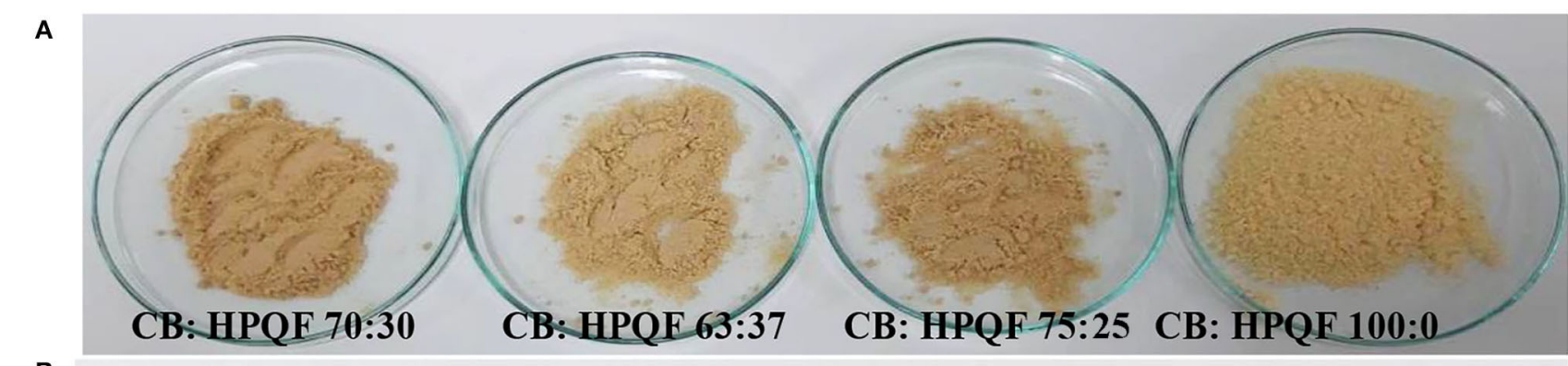

B

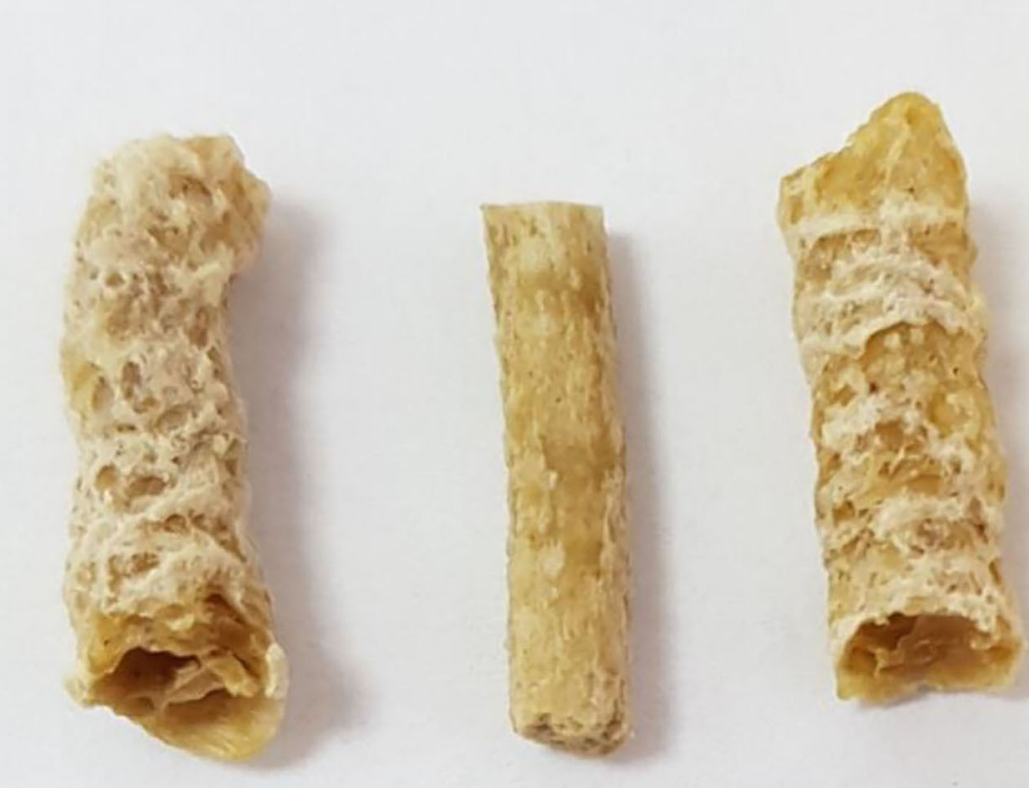

CB: HPQF 70:30

CB: HPQF 63:37

CB: HPQF 75:25 CB: HPQF 100:0

FIGURE 2 | Digital image of non-extruded up (A) and extruded flours of cereal mixes from hyper-protein quinoa flour down (B).

TABLE 5 | Pasting properties of non-extruded and extruded samples.

\begin{tabular}{|c|c|c|c|c|c|c|c|}
\hline Sample & $\begin{array}{c}\text { Peak viscosidad } \\
\text { (Pa.s) }\end{array}$ & $\begin{array}{c}\text { Peak tiempo } \\
\text { (s) }\end{array}$ & $\begin{array}{c}\text { Through } \\
\text { (Pa.s) }\end{array}$ & $\begin{array}{l}\text { Final viscosity } \\
\text { (Pa.s) }\end{array}$ & $\begin{array}{c}\text { Pasting } \\
\text { temperature } \\
\left({ }^{\circ} \mathrm{C}\right)\end{array}$ & Breakdown & $\begin{array}{c}\text { Setback } \\
\text { (Pa.s) }\end{array}$ \\
\hline CB: HPQF 75:25 & $0.403 \pm 0.01^{a}$ & $260 \pm 2.82^{c}$ & $0.151 \pm 0.01^{a}$ & $0.47 \pm 0.05^{\mathrm{a}}$ & $77.75 \pm 4.88^{b}$ & $0.252 \pm 0.08^{a}$ & $0.31 \pm 0.041^{a}$ \\
\hline CB: HPQF 70:30 & $0.376 \pm 0.09^{a}$ & $290 \pm 5.66^{b}$ & $0.150 \pm 0.02^{a}$ & $0.470 \pm 0.09^{a}$ & $80.70 \pm 1.13^{\mathrm{ab}}$ & $0.225 \pm 0.07^{\mathrm{a}}$ & $0.32 \pm 0.07^{\mathrm{a}}$ \\
\hline CB: HPQF 63:37 & $0.3305 \pm 0.02^{\mathrm{a}}$ & $292 \pm 0.01^{b}$ & $0.155 \pm 0.02^{\mathrm{a}}$ & $0.46 \pm 0.07^{\mathrm{a}}$ & $80.95 \pm 0.35^{\mathrm{ab}}$ & $0.175 \pm 0.00^{\mathrm{a}}$ & $0.30 \pm 0.05^{a}$ \\
\hline \multicolumn{8}{|c|}{ Non-extruded samples } \\
\hline CB: HPQF 75:25 & $1.278 \pm 0.192^{b}$ & $317 \pm 9.89^{a}$ & $0.887 \pm 0.00^{b}$ & $3.04 \pm 0.02^{b}$ & $85.90 \pm 1.84^{a}$ & $0.391 \pm 0.018^{b}$ & $2.15 \pm 0.018^{b}$ \\
\hline CB: HPQF 70:30 & $1.38 \pm 0.03^{b}$ & $320 \pm 2.83^{a}$ & $0.876 \pm 0.01^{b}$ & $3.00 \pm 0.04^{b}$ & $86.35 \pm 0.64^{a}$ & $0.507 \pm 0.01^{\mathrm{b}}$ & $2.13 \pm 0.02^{b}$ \\
\hline CB: HPQF 63:37 & $1.155 \pm 0.07^{b}$ & $322 \pm 1.42^{\mathrm{a}}$ & $0.797 \pm 0.00^{b}$ & $2.52 \pm 0.15^{b}$ & $87.00 \pm 0.28^{a}$ & $0.359 \pm 0.06^{b}$ & $1.72 \pm 0.14^{b}$ \\
\hline CB: HPQF 100:0 & $2.801 \pm 0.336^{a}$ & $323 \pm 1.43^{\mathrm{a}}$ & $1.487 \pm 0.09^{a}$ & $5.51 \pm 0.33^{\mathrm{a}}$ & $87.15 \pm 0.21^{a}$ & $1.314 \pm 0.024^{\mathrm{a}}$ & $4.03 \pm 0.23^{a}$ \\
\hline
\end{tabular}

For each parameter, different letters indicate significant differences at $p<0.05$. 
A

Non-extruded samples

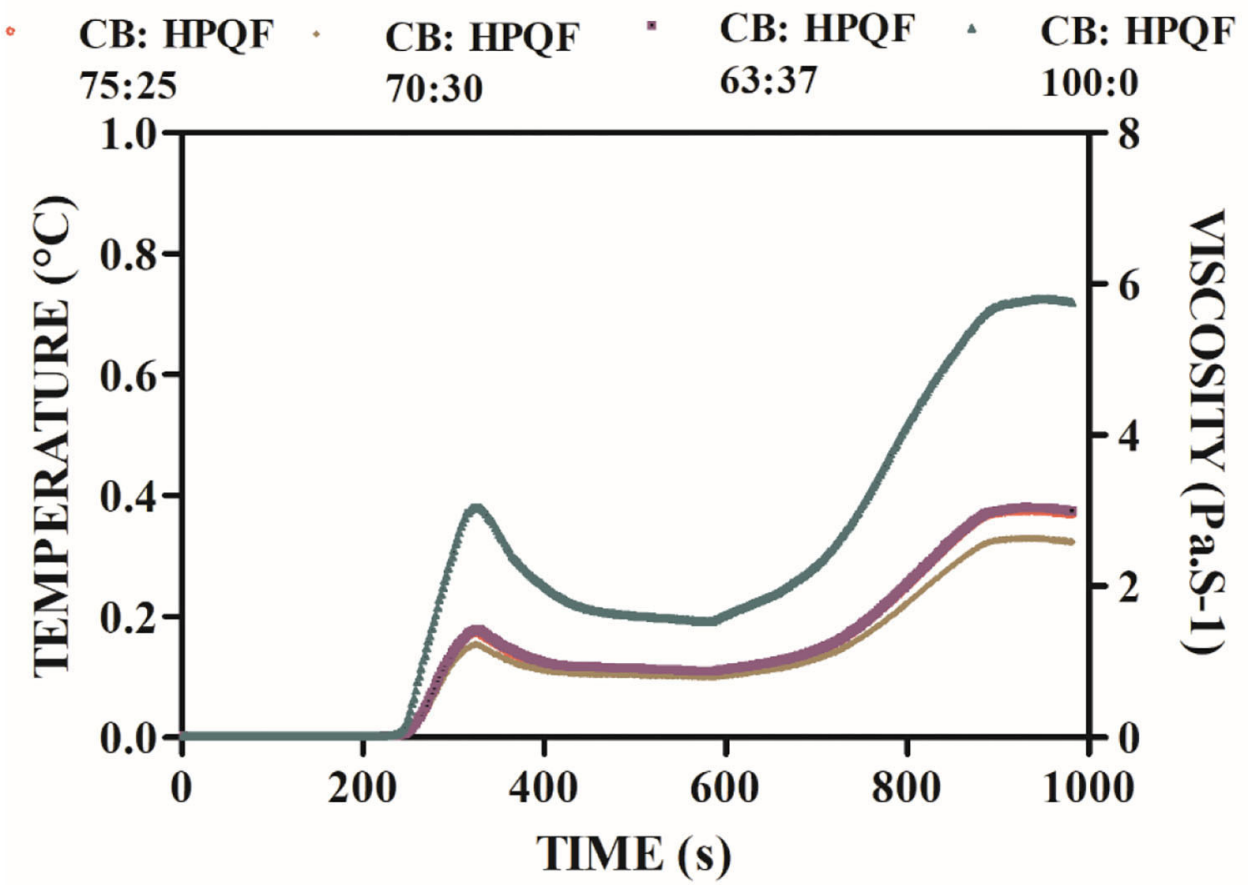

B

Extruded samples

CB: HPQF -CB: HPQF -CB: HPQF -CB: HPQF $\begin{array}{llll}75: 25 & 75: 25 & 75: 25 & 100: 0\end{array}$

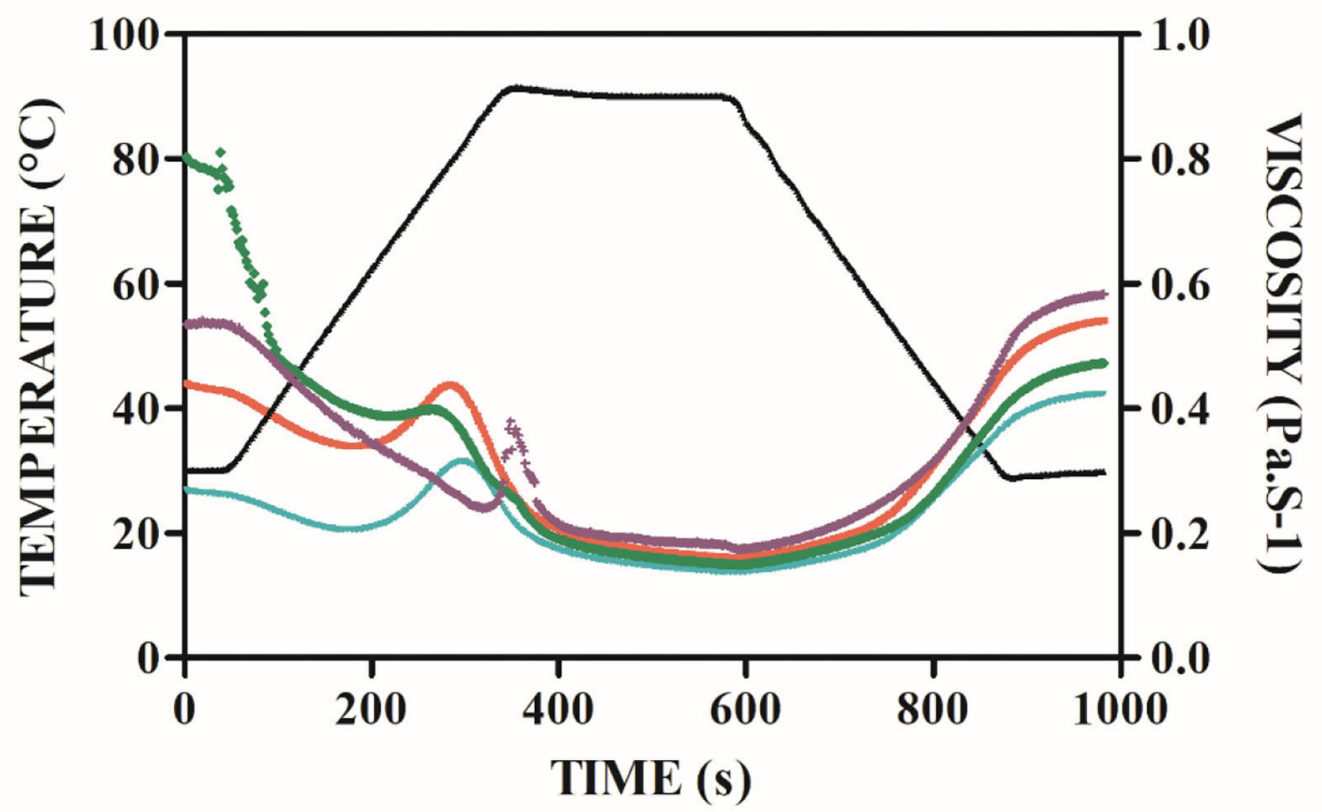

FIGURE 3 | Pasting properties of non-extruded samples (A) and extruded samples (B), obtained with different amounts of hyper-protein quinoa flour. 
reflects the starch transformation during the extrusion, which can indirectly quantify its degradation degree (Fallahi et al., 2016).

The fact extruded mixture viscosities are unaffected by extrusion temperature; starches behave the same at the temperature profile employed; quinoa starches present in the extrudates gel faster and at lower temperatures compared to corn starch may be due to the more organized crystalline structure of corn starch (Fallahi et al., 2016).

Although there was no significant difference between the initial and final extrudates' viscosity, the lower values are directly associated with lower expansion index values. In this study, extrudates with $37 \%$ quinoa presented the lowest ER value according to the lowest viscosity value, also reported by Fallahi et al. (2016).

"Breakdown" values of non-extruded samples decreased after adding quinoa flour, showing the better stability of non-extruded samples during mixing at extrusion temperature, as quinoa starch of various genotypes has a lower amylose content (7-27\%), its size can vary between $(0.5-3 \mu \mathrm{m}$ in diameter) and these granule characteristics make quinoa starch a successful candidate for stabilizing food grade emulsions (Wang and Zhu, 2016). In their results, Jozinović et al. (2016) report a positive effect of the interaction between temperature and adding high fiber content spelt flour on the increase of "breakdown" values, which is attributed to the effect of fiber within the starch matrix that was enhanced by temperature. Breakdown values of extruded samples were lower regarding non-extruded samples and the positive effect of quinoa flour addition on viscosity stability was higher at $37 \%$ concentration.

"Setback" values are the indicator of retrogradation and rearrangement of starch molecules during the cooling process (Jozinović et al., 2016). "Setback" values decreased significantly after extrusion, showing that the extruded samples were less prone to retrogradation and hence extrusion may contribute for the final product's stabilization (Wani and Kumar, 2019).

The mixture of cereals and HPQF has a lower "retrogradation" value, regarding the extrudate mixture without quinoa. This may be due to a higher fiber content in the samples with quinoa flour, as presented in the proximate analysis, which is consistent with other studies' findings (Nascimento et al., 2012; Jozinović et al., 2016).

\section{REFERENCES}

Abugoch, J. L. E. (2009). Quinoa (Chenopodium Quinoa Willd.): composition, chemistry, nutritional, and functional properties. In: Advances in Food and Nutrition Research. 1st Edn. Vol. 58. Amsterdam: Elsevier Inc. doi: 10.1016/S1043-4526(09) 58001-1

Alam, M. S., Kaur, J., Khaira, H., and Gupta, K. (2016). Extrusion and extruded products: changes in quality attributes as affected by extrusion process parameters: a review. Crit. Rev. Food Sci. Nutrition 56, 445-473. doi: 10.1080/10408398.2013.77 9568

Avila Ruiz, G., Arts, A., Minor,M., and Schutyser, M. (2016). A hybrid dry and aqueous fractionation method to obtain proteinrich fractions from Quinoa (Chenopodium quinoa willd).

\section{CONCLUSIONS}

Results from present study show that the addition of HPQF to the $\mathrm{CB}$ increased the protein content of the snacks, decreased the IE and increased the ED of the extrudates. The results of the texture properties coincided with the results of the IE measurements, i.e., extrudates with lower values of IE had higher hardness and lower fracturability. The addition of quinoa flour and the extrusion process significantly changed the color. WAI decreased and WSI increased with the addition of quinoa flour to the $\mathrm{CB}$, but after the extrusion process both parameters increased significantly. The addition of HPQF and the extrusion process caused the decrease of maximum viscosity values, the extruded samples were less prone to retrogradation.

The results obtained in this research indicate that hyperprotein quinoa flour can be successfully incorporated into a cereal mixture because it raises the protein content; however, for the production of snack products, research should be done on how to improve the physical properties.

\section{DATA AVAILABILITY STATEMENT}

The original contributions presented in the study are included in the article/supplementary material, further inquiries can be directed to the corresponding authors.

\section{AUTHOR CONTRIBUTIONS}

KM-P and DR-A: methodology, formal analysis, investigation, and writing original draft. AP-P: experimental execution and data collection. JB-G: conceptualization, content, and data curation. KM-P, JH-C, and DR-A: methodology and formal analysis. JH-C: supervision. All authors contributed to the article and approved the submitted version.

\section{FUNDING}

This work has been fully financed by the Colombian General Reimbursement System, the University of Cauca and SEGALCO S.A.S., within the framework of the SGR BPIN 2020000100052 Project.
Food Bioprocess Tech. 9, 1502-1510. doi: 10.1007/s11947-0161731-0

Caperuto, L. C., Amaya-Farfan, J., and Camargo, C. R. O. (2001). Performance of Quinoa (Chenopodium Quinoa Willd) flour in the manufacture of gluten-free spaghetti. J. Sci. Food Agricul. 81, 95-101. doi: 10.1002/10970010(20010101)81:1andlt;95::AID-JSFA786andgt;3.0.CO;2-T

Chadha, D., Young, O., Otter, D., and Kam, R. (2021). Physical analysis of friction cooked RTE snacks. Innovat. Food Sci. Emerg. Tech. 69:102643. doi: 10.1016/j.ifset.2021.102643

D’Amico, S., Sarah, J., Gabor, B., Maike, F., Mario, J., Sandor, T., et al. (2019) Abrasive milling of quinoa: study on the distribution of selected nutrients and proteins within the quinoa seed kernel. J. Cereal Sci. 86, 132-138. doi: 10.1016/j.jcs.2019.01.007

Fallahi, P., Muthukumarappan, K., and Rosentrater, K. A. (2016). Functional and structural properties of corn, potato, and cassava starches as 
affected by a single-screw extruder. Int. J. Food Propertes 19, 768-788. doi: 10.1080/10942912.2015.1042112

Gulati, P., Brahma, S., and Rose, D. J. (2020). Impacts of Extrusion Processing on Nutritional Components in Cereals and Legumes: Carbohydrates, Proteins, Lipids, Vitamins, and Minerals. Extrusion Cooking. Elsevier Inc. doi: 10.1016/B978-0-12-815360-4.00013-4

Haros, C. M. (2017). "Separation of kernel components," in Pseudocereals: Chemistry and Technology, ed John Wiley \& Sons (New York, NY: John Wiley \& Sons, Ltd), 140-162.

Jabeen, A., Naik, H. R., Jan, N., Hussain, S. Z., Shafi, F., and Amin, T. (2021). Numerical optimization of process parameters of water chestnut flour incorporated corn-based extrudates: characterizing physicochemical, nutraceutical, and storage stability of the developed product. J. Food Process. Preserv. 45:e15569. doi: 10.1111/jfpp.15569

Jozinović, A., Šubarić, D., Ačkar, D., Babi,ć, J., and Miličević, B. (2016). Influence of spelt flour addition on properties of extruded products based on corn grits. J. Food Eng. 172, 31-37. doi: 10.1016/j.jfoodeng.2015. 04.012

Karkle, E. L., Alavi, S., and Dogan, H. (2012). Cellular architecture and its relationship with mechanical properties in expanded extrudates containing apple pomace. Food Res. Int. 46, 10-21. doi: 10.1016/j.foodres.2011.11.003

Li, X., Masatcioglu, M. T., and Koksel, F. (2019). Physical and functional properties of wheat flour extrudates produced by nitrogen injection assisted extrusion cooking. J. Cereal Sci. 89:102811. doi: 10.1016/j.jcs.2019.102811

Martin, A. V., Schmidt, R. O., Jürgen, B., Ortner, E., and Mittermaier, S. (2020). Texture, sensory properties and functionality of extruded snacks from pulses and pseudocereal proteins. J. Sci. Food Agriculture. doi: 10.1002/jsfa.11041 [Online ahead of print].

Nascimento, E. M., Carvalho, C. W., Takeiti, C. Y., Freitas, D. G. C., and JLR Ascheri (2012). Use of sesame oil cake (Sesamum indicum L.) on corn expanded extrudates. Food Res. Int. 45, 434-443. doi: 10.1016/j.foodres.2011.11.009

Ondo, S. E., Singkhornart, S., and Ryu, G. H. (2013). Effects of die temperature, alkalized cocoa powder content and $\mathrm{CO}_{2}$ gas injection on physical properties of extruded cornmeal. J. Food Eng. 117, 173-182. doi: 10.1016/j.jfoodeng.2013.01.040

Pasqualone, A., Costantini, M., Labarbuta, R., and Summo, C. (2021). Production of extruded-cooked lentil flours at industrial level: effect of processing conditions on starch gelatinization, dough rheological properties and technofunctional parameters. $L W T$ 147:111580. doi: 10.1016/j.lwt.2021.111580

Pilli, T., Derossi., Talja, R. A., Jouppila, K., and Severini, C. (2012). Starch-lipid complex formation during extrusion-cooking of model system (Rice starch and oleic acid) and real food (rice starch and pistachio nut flour). Eur. Food Res. Tech. 234, 517-525. doi: 10.1007/s00217-012-1662-6

Polo, M. P., Roa, D. F., and Bravo, J. E. (2021). Propiedades Reológicas de Quinua (Chenopodium Quinoa Wild) Obtenidas Mediante Molienda Abrasiva y Tratamiento Térmico. Información tecnológica. 32, 53-64. doi: $10.4067 /$ S0718-07642021000600053

Ramos Diaz, J. M., Suuronen, J. P., Deegan, D. K., Serimaa, R., Tuorila, H., and Jouppila, K. (2015). Physical and sensory characteristics of corn-based extruded snacks containing amaranth, Quinoa and Kañiwa Flour. LWT 64, 1047-1056. doi: 10.1016/j.lwt.2015.07.011

Reichert, R. D., and Youngs, C. G. (1976). Dehulling cereal grains and grain legumes for developing countries. I. Quantitatitive comparision between Attrition- and Abrasive-Type Mills. Cereal Chemists. 53, 829-30.

Roa, D., Bravo, J., and González, C. (2019). Moderling of particle size and energetic requirement in amaranth grain ball-milling. Revista U.D.C.A Actualidad and Divulgación Científica. 22:2:e1183.

Roa-Acosta, D. F., Bravo-Gómez, J. E., García-Parra, M. A., Rodríguez-Herrera, R., and Solanilla-Duque, J. F. (2020). Hyper-protein quinoa flour (chenopodium quinoa wild): monitoring and study of structural and rheological properties. LWT 121:108952. doi: 10.1016/j.lwt.2019.108952
Sarawong, C., Schoenlechner, R., Sekiguchi, K., Berghofer, E., and Perry, K. W., Ng. (2014). Effect of extrusion cooking on the physicochemical properties, resistant starch, phenolic content and antioxidant capacities of green banana flour. Food Chem. 143, 33-39. doi: 10.1016/j.foodchem.2013.07.081

Schlinkert, C., Marleen, G., Jeroen, B., Maartje, P., and Denise de, R. (2020). The snack that has it all: people's associations with ideal snacks. Appetite 152:104722. doi: 10.1016/j.appet.2020.104722

Sezgin, C. A., and Sanlier, N. S. (2019). A new generation plant for the conventional cuisine: Quinoa (Chenopodium Quinoa Willd.). Trends Food Sci. Tech. 86, 51-58. doi: 10.1016/j.tifs.2019.02.039

Shah, F. H., Sharif, M. K., Butt, M. S., and Shahid, M. (2016). Development of protein, dietary fiber and. J. Texture Stud. 48:230. doi: 10.1111/jtxs.12231

Sobowale, S. S., Kewuyemi, Y. O., and Olayanju, A. T. (2021). Process optimization of extrusion variables and effects on some quality and sensory characteristics of extruded snacks from whole pearl millet-based flour. SN Appl. Sci. 3. doi: $10.1007 / \mathrm{s} 42452-021-04808-\mathrm{w}$

Tas, A. A., and Shah, A. U. (2021). The replacement of cereals by legumes in extruded snack foods: science, technology and challenges. Trends Food Sci. Tech. 116, 701-711. doi: 10.1016/j.tifs.2021. 08.016

Wang, S., and Zhu, F. (2016). Formulation and quality attributes of quinoa food products. Food Bioprocess Techn. 9, 49-68. doi: 10.1007/s11947-015-1584-y

Wani, S. A., and Kumar, P. (2016). Development and parameter optimization of health promising extrudate based on fenugreek oat and pea. Food Biosci. 14, 34-40. doi: 10.1016/j.fbio.2016.02.002

Wani, S. A., and Kumar, P. (2019). Influence on the antioxidant, structural and pasting properties of snacks with fenugreek, oats and green pea. J. Saudi Soc. Agricul. Sci. 18, 389-395. doi: 10.1016/j.jssas.2018. 01.001

Ye, J., Chen, Z., Liu, Q., and Xu, C. (2018). Tin sulphide nanoflowers anchored on three-dimensional porous graphene networks as highperformance anode for sodium-ion batteries. J. Colloid Interface Sci. 516, 1-8. doi: 10.1016/j.jcis.2018.01.045

Zapana, F., Bruijn, J., Vidal, L., Melín, P., González, M. E., Cabrera, G., et al. (2020). Physical, chemical and nutritional characteristics of puffed quinoa. Int. J. Food Sci. Tech. 55, 313-322. doi: 10.1111/ijfs. 14290

Zhu, L. J., Shukri, R., De Mesa-Stonestreet, N. J., Alavi, S., Dogan, H., and Shi, Y. C. (2010). Mechanical and microstructural properties of soy protein - high amylose corn starch extrudates in relation to physiochemical changes of starch during extrusion. J. Food Eng. 100, 232-238. doi: 10.1016/j.jfoodeng.2010.04.004

Conflict of Interest: The authors declare that the research was conducted in the absence of any commercial or financial relationships that could be construed as a potential conflict of interest.

Publisher's Note: All claims expressed in this article are solely those of the authors and do not necessarily represent those of their affiliated organizations, or those of the publisher, the editors and the reviewers. Any product that may be evaluated in this article, or claim that may be made by its manufacturer, is not guaranteed or endorsed by the publisher.

Copyright (C) 2022 Muño-Pabon, Parra-Polanco, Roa-Acosta, Hoyos-Concha and Bravo-Gomez. This is an open-access article distributed under the terms of the Creative Commons Attribution License (CC BY). The use, distribution or reproduction in other forums is permitted, provided the original author(s) and the copyright owner(s) are credited and that the original publication in this journal is cited, in accordance with accepted academic practice. No use, distribution or reproduction is permitted which does not comply with these terms. 